\title{
" Hospital Organization Charts and It's Benefits to Hospitals Management "
}

\author{
Authors \\ Moataz Nagib Aly email 1; Heba Elsayed2; Ahmed Mokhtar Ibrahem3; \\ Mohamed Shata4; Norhan Hossam eldeens; Nada Hossam Eldeen6 \\ 1Al Salam hospital Port Said \\ 2Port Said University \\ 3ICU specialist Al Salam hospital \\ 4National heath care authority Port Said \\ 5Al Mobara hospital Port Said \\ 6Port Said
}

\begin{abstract}
The paper approach for assessment of the organizational creation \& exhibitions via the Balanced Scorecard of personal hospitals via way of means of specializing in pinnacle management's insights. A prepared ballot becomes applied and ninety seven non-public clinics enrolled with the Association of Private Hospitals Malaysia had been remembered for the study. In total, 39 reactions had been gotten which introduced approximately a commonly usable response tempo of $40.2 \%$. The clean consequences delineated that maximum of
\end{abstract}


the non-public clinics that take at the Balanced Scorecard are especially focused and formalized. These non-public emergency clinics offered in to formalized standards furthermore, composed traditional method to assure the management and management of the health supplier's act as according to embraced values. Accordingly, there may be an proper connection to in addition evolved exhibitions interior this location on the important thing viewpoints: inward commercial enterprise measures, affected person fine administrations, protection and success, hierarchical gaining knowledge of and development, and monetary. Up to this point, however the evidence from this assessment that may be ascribed to turning into successful hospital treatment suppliers, drivers applied which fuse obligation, trustworthiness, obligation and simplicity in comparing exhibitions may be taken up. This paper complements the constrained scholarly BSC writing and successful problems referring to fine enhancements and affected person success within the non-public hospital treatment location

\section{Keywords:}

Organization chart - work organization - authority centralization - Formalization

\section{Introduction}

Medical offerings enterprise has emerge as one of the world's biggest, highpriced and fast growing corporations because it shapes a huge piece of a nation's economy. Both personal and public scientific offerings institutions want to control an unsound weather due to distinct powers like speedy extrade of innovation, section thing and extrade in methods of life (Koumpouros, 2013). The everyday every year improvement of 2.6 according to penny all through the subsequent 4 years (2014-2017) has come down at the legislatures, scientific offerings organizations, safety places of work and consumers to triumph over problems like consistent sicknesses, excessive medical prices, conflicting high-satisfactory administrations, maturing population and imbalanced admittance to thoughts due to laborers 
deficiencies simply as innovation and basis impediments. This is due to the growth in population improvement which has triggered the ascent withinside the sponsoring medical advantages according to man or woman to 4.4. Percent from 2014 till 2017 (Deloitte, 2014). The pinnacle problems for public vicinity in 2014 are overseeing scientific offerings prices and pleasant consumers want for evenhanded and high-satisfactory admittance to scientific offerings. Subsequently, the paper intends to measure the layout of conscious personal emergency clinics simply as their exhibitions thru Balanced Scorecard. A succesful hospital treatment dealer could have to make use of drivers which fuse liability, respectability, duty and simplicity in comparing exhibitions. The hospital treatment institutions standard are scuffling with to control increasing wellness charges whilst presenting awesome varieties of help to clients at decrease charges (Deloitte, 2014). Nonetheless, in assessment with distinct corporations, the hospital treatment enterprise is an exorbitant enterprise because the medical exercise these days calls for greater usage of innovation and current medical trials (Boon, 2002). The extra a part of the clinics burn thru hundreds of thousands to shop for and to overtake their medical varieties of gear. Huge problems regarded through personal scientific clinics do not forget problems for assembly affected person achievement (Silow-Carroll, 2008) and, thoroughly preserving up with their sports and running on their economic duty due to firm contest on this vicinity. Moullin (2004) clarified that sufferers paying excessive assembly costs \& luxurious medical advantages introduced through scientific clinics as such they request quick retaining up an excellent possibility to look their doctors, circulate to ward and get take a look at results. Be that because it may, due to the complicated practical cycles and distinct affected person conditions, it brought about a extensive delay. The gift sittuation triggered affected person sadness and elevated in quiet grievances in the direction of the scientific sanatorium administrations on the way to then, at that factor have an effect on the scientific sanatorium execution. Gurd and GAO (2008) referred to as 
interest to that chronic achievement is a fashionable pointer of sanatorium's inward cycle and management in the direction of their client which accordingly effect affected person dependability and its staying power withinside the critical weather. Accordingly, Silow-Carroll (2008) underlines the requirement for advanced exhibition estimation for personal scientific clinics. The BSC noticed because the maximum affordable shape can provide essential records referring to the hierarchical indoors and out of doors elements in an effort to consequently upload to the association's prosperity. To the diploma of the specialist's information, there are limited investigations led to research the exhibition of hospital treatment regions in Malaysia. The extra a part of those examinations zeroed in on distinct regions just like the improvement business (Hiap, 2012), fabricating enterprise, public vicinity, execution of BSC in a linked to Government organization, reception \& execution of BSC of Malaysian organizations. Nonetheless, in view of a survey of pertinent writing in Malaysia, there's likewise a scarcity withinside the give attention to BSC withinside the close by hospital treatment vicinity. Along those lines, the problems tested above gave a risk to this overview to be done. Along those lines, this overview intends to assess the authoritative creation of Malaysian personal emergency clinics and their exhibitions making use of the Balanced Scorecard simply as similar to being a reliable hospital treatment dealer. This paper is coordinated into 5 regions. The predominant section offers the muse of the overview. The $2 \mathrm{~d}$ and 0.33 segments gift the writing audit and exploration strategy, separately. The fourth vicinity examines the aftereffects of the overview. The which means of the overview, its restriction and notion for destiny paintings are added withinside the final

\section{2.0 Review of Literature}

2.1 Measurment of Performance System 
2. Execution Measurement System is a route of surveying the affiliation development in undertaking the goals and goals. PMS may be in economic and non-economic measures. As consistent with estimating execution isn't always simply to apprehend the modern-day presentation of the enterprise but it likewise allows the enterprise to carry out higher later on. PMS is pressing in enterprise because it survey the adequacy of the affiliation's sports to be able to make contributions in making really well worth to companions simply because the effectiveness of the alternate of belongings into products/benefits, the character of merchandise/administrations gave also, the consequences of the affiliation action performance measurement can likewise make some sizeable commitments to affiliation, for example, by increase the foundation to carry out, undertaking authoritative goals, running on representatives' functionality and explaining the meanings of the work. Various PMSs like Six Sigma, Knowledge Management, Quality Program had been created furthermore, implemented to supervise authoritative motion and execution. As indicated through Martinez (2005), affiliation's want to 0 in at the 'inward affects' of PMS because it will straightforwardly effect the manner institutions works. This is for the reason that the 'inward affects' are created in the affiliation and they may be the factors that affect affiliation's benefit, notoriety and efficiency (Martinez, 2005). Thusly, it's far sizeable for affiliation to recognize the affects of PMS to enhance its advantages. Accordingly, one method to perform that is the usage of BSC as a presentation estimation framework. BSC is regarded as a remarkable asset for authoritative alternate and as a effective exhibition estimation framework at each the humans and authoritative levels. The following location will assume at the Ballanced Scorecard.

\subsection{Balanced Scorecard.}

Balanced Scorecard (BSC) created in 1992 is an management bookkeeping tool that translates an affiliation's foremost goal, strategies and goals into execution estimates which comprise 4 viewpoints, for example, financial, purchaser, 
inward enterprise cycle and gaining knowledge of and development . The BSC is formally characterised as a multidimensional manner to cope with degree the management execution thru reading connection among the hierarchical structures and useful exhibitions. The essential best of a BSC is it accentuates on financial factors of view and non-financial viewpoints) simply as becoming a member of the critical financial targets with normal duties withinside the affiliation. The financial and non-financial measures have been consolidated in BSC and ultimately related everything of the viewpoints that cope with the normally speakme hierarchical presentation into organization strategies. The expression "adjusted" suggests that the framework is adjusted among the existing second and lengthy haul goals, financial and non-financial measures, slacking and riding recommendations simply as internal and outer exhibitions factors of view (Vesty, 2004). The expression "scorecard" is a technique of archiving the events of the affiliation exercises (Christesen, 2008). As in line with Atkinson (2006), the BSC facilities across the management attention of the exhibition drivers through unmistakably uplifting the addition of "lead" and "slack" recommendations. It is in view that a respectable BSC have to comprise a mix of lead what is more, slack recommendations or in any other case known as "Execution Drivers" and "Results Measures" individually. It is moreover referred to through Kaplan and Norton (2001) that a mix of lead and slack recommendations will empower employees to split among measurers they could not take care of and measures that may be impacted through their activity. Driving markers or in any other case known as temporary execution drivers provide statistics referring to momentum execution that maximum likely could be the drivers of destiny execution . For instance, object best is the affiliation's profits key pointer; on this way it's far critical to assure regular development in object best to pressure offers and execution of the affiliation. Aside from that clarified that purchaser standpoint withinside the BSC is one of the foremost markers because it enables the affiliation to survey purchaser loyalty toward its objects and administrations. 


\subsection{Balanced Scorecard in Healthcare management}

In view of an audit of in advance investigations, it has a tendency to be reasoned that maximum of the evaluation used the contextual evaluation as Economics and Financ0 eprofesors made their exam technique. Other than that, the ones examinations zeroed in at the utility and utilization of BSC withinside the hospital treatment area. For example, Mcwhert (2012) carried out the BSC device withinside the Calverrt Memorial Hospital thru case focus on technique. He discovered that, BSC had the choice to address the accomplishment of lengthy haul and gift second of the health facility undertaking and vision. What's more, Lin, and Zhang (2016) researched the glide usage of BSC withinside the China's public emergency health facility via way of means of the use of assessment strategy. They identified that the BSC has decidedly swayed the clinical health facility organization. Further to that, they exposed that there are extraordinary variables that affected the BSC execution, for example, health facility's innovation great and scientific hardware Table 1 gift rundowns of BSC packages the Healthcare enterprise in extraordinary nations, individually

Authoritative creation portrays an affiliation's right saying connections, allotment of duty simply as method which can be finished amongst hierarchical individuals. It likewise indicates a intending with sport plan of hierarchical errands and sports characterizes hierarchical creation as a "formal allotment of labor legal responsibility and regulatory aspect to manipulate and include paintings sports". As indicated with the aid of using Hunter (2002), affiliation of labor is a key aspect that affects the performance of the affiliation as the location courting comes to a decision the way wherein the representatives paintings. Fundamentally, authoritative layout incorporates of labor department and coordination system (Meijaard et al., 2005). Comprehensively talking, authoritative layout is predominantly vast for dynamic interplay because it 
includes the traits of energy centralization, order degrees and flat reconciliation (Hao et al., 2012). Three maximum vast views in hierarchical layout contained centralization, formalization and coordination. Centralization alludes to the grouping of the board and pressure of dynamic interplay at the very best factor of an affiliation's chain of importance (Mahmoudsalehi et al., 2012). They similarly introduced that affiliation with excessive centralization will in fashionable restriction collaborations most of the affiliation individuals, frustrates innovative solution for problems and decreases the danger for person flip of events. Mahmoudsalehi et al., (2012) featured that centralization is profoundly diagnosed with the dynamic pressure with the aid of using the pinnacle management of the affiliation. Subsequently, it offers a bit designation of dynamic potential to the employees and inflicting a non-participatory weather that diminishes correspondence simply as errand affiliation most of the representatives. Other than that, Mahmoudsalehi et al. (2012) expressed that excessive centrallization hinders the possibility for employee development and development. Then again, low centralization will help employee's inventiveness and affiliation in affiliation projects . Mahmoudsalehi et al., (2012) relates formalization to the diploma of labor jobs inner an affiliation which can be prepared and sports of the representatives are administered with the aid of using regulations and strategies. Association with excessive formalization provides development inner affiliation with the aid of using putting a manageable recommendations and structures to decrease uncertainty and flexibility of representatives (Pertusa-Ortega et al., 2010). In the meantime, reconciliation is characterised because the diploma to the numerous diploma of representatives withinside the affiliation that may be facilitated thru the right coordination instrument (Liao, Chuang, and To, 2011). Be that because it may, somewhat, hierarchical layout is stimulated with the aid of using the out of doors weather (Nahm et al., 2003). As in step with Ireland et al. (2013), it's miles tough to foster an authoritative layout that viably upholds the corporation method due to the vulnerability of causality withinside the international economic system fast 
modifications and severe enterprise weather. All matters considered, authoritative creation assumes pivotal component in supporting the affiliation to perform higher execution (Weir, 1995). The accomplishment of any affiliation method is based substantially upon its consistency with the authoritative layout (Jabnoun, 2005). Subsequently, to paintings on their presentation, the more a part of the corporations observed a fruitful corporation with the aid of using taking up their hierarchical layout, empowering tendencies and gaining from their experience. In mild of the verbal exchange above

Research

Method:

A observe on BSC reception became directed on personal clinics enrolled beneathneath the Association of Private Hospital of Malaysia (APHM). There had been 117 institutions recorded withinside the APHM webweb page as at April 2014. Nonetheless, absolutely the variety of 117 included the centers and nursing domestic which aren't affordable to be remembered for this observe as this evaluation zeroed in on personal emergency clinics. The unique variety of personal scientific hospital next to barring centers and nursing houses are ninety seven. Consequently the complete population of ninety seven personal emergency clinics became taken as the instance for this evaluation. The goal respondents had been the Executive Officer (CEO), Chief Financial Officer (CFO), Chief Operating Official (COO), General Manager , Head of Department or Accountant. This is at the grounds that, they related to surely figuring out and may supply reliable records referring to the affiliation traits simply as its activities (Sony and Naik, 2012). Besides, as indicated through Mcwhirt (2013) the management institution related to the execution of BSC internal an affiliation, contained the CEO, head operating official, administrators of HR, cash and records administrations. Mcwhirt(2013) in addition clarified that, the management institution could foster a gadget depending on the BSC to satisfy the institutions goals and vision. In that capacity, the selection of the goal respondents for this evaluation is considered as proper. Information became accumulated firsthand from the respondents through using the approach for 
polls. The ballot is basically partitioned into 4 segments. Segment A spotlights at the affiliation's traits like age, variety of representatives and variety of beds. Area B facilities at the hierarchical construction. In the intervening time Section $\mathrm{C}$ investigated the reception of BSC withinside the personal clinics, Section D try and accumulate records at the respondent's experience. The goal respondents had been the Chief Executive Officer (CEO), Chief Financial Officer (CFO), Chief Operating Officer (COO), General Manager, Head of Department or Accountant. This is at the grounds that, they related to figuring out and may supply reliable records referring to the affiliation traits simply as its activities (Sony and Naik, 2012) Review surveys had been disseminated through mail to each one of the ninety seven personal scientific clinics enrolled with APHM and simply 39 reactions had been gotten after 3 next meet-ups. The through and massive usable response price became $40.2 \%$.

4.0. Results and Discussion

This section discusses the descriptive results on respondents' background, BSC adoption, organizational characteristics and organizational performance.

4.1. Respondents' background:

Table 2. Presents the outcomes on respondents' experience. The respondents are from various progressive levels and useful regions. Just beneath half of them have been utilized by the emergency clinics for at least five years. Likewise, most of the respondents have gone to tertiary schooling with a few of them with bosses' and furthermore proficient capabilities. Further to that, there are practically equivalent conveyances between the sexual orientations. Generally, the respondents' experience showed somewhat that they have adequate experience and information about the separate lodgings where they have been utilized. 
Table 2. Respondents' Background

\begin{tabular}{|c|c|c|c|c|}
\hline$(\mathrm{N}=39)$ & Frequency & Percent & $\begin{array}{l}\text { Valid } \\
\text { Percent }\end{array}$ & $\begin{array}{l}\text { Cumulative } \\
\text { Percent }\end{array}$ \\
\hline $\begin{array}{lrr}\text { Position } & & \\
\text { Head of } & \text { Organization } \\
\text { Assistant } & \text { manager } \\
\text { Manager } & \end{array}$ & $\begin{array}{l}11 \\
4 \\
24\end{array}$ & $\begin{array}{l}28.2 \\
10.3 \\
61.5\end{array}$ & $\begin{array}{l}28.2 \\
10.3 \\
61.5\end{array}$ & $\begin{array}{l}28.2 \\
38.5 \\
100.0\end{array}$ \\
\hline $\begin{array}{l}\text { Current } \\
\text { H.R. } \\
\text { Financial } \\
\text { Operational } \\
\text { Public Relations and } \\
\text { Marketing }\end{array}$ & $\begin{array}{l}23 \\
8 \\
4 \\
4\end{array}$ & $\begin{array}{r}59.0 \\
20.5 \\
10.3 \\
10.3\end{array}$ & $\begin{array}{r}59.0 \\
20.5 \\
10.3 \\
10.3\end{array}$ & $\begin{array}{l}59.0 \\
79.5 \\
89.7 \\
100.0\end{array}$ \\
\hline 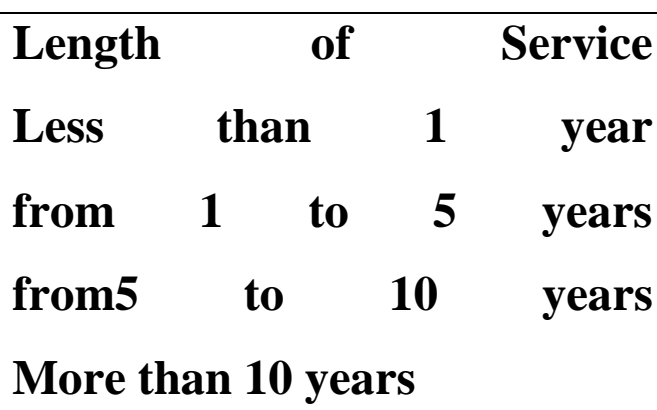 & $\begin{array}{l}1 \\
21 \\
15 \\
2\end{array}$ & \begin{tabular}{l|}
2.6 \\
53.8 \\
38.5 \\
5.1
\end{tabular} & \begin{tabular}{l|}
2.6 \\
53.8 \\
38.5 \\
5.1
\end{tabular} & $\begin{array}{l}2.6 \\
56.4 \\
94.9 \\
100.0\end{array}$ \\
\hline $\begin{array}{ll}\text { Highest educational } & \text { level } \\
\text { Diplomas } & \\
\text { Bachelors } & \text { Degrees } \\
\text { Masters } & \text { Degrees } \\
\text { Professional service } & \end{array}$ & $\begin{array}{l}5 \\
21 \\
2 \\
11\end{array}$ & $\begin{array}{l}12.8 \\
53.8 \\
5.1 \\
28.2\end{array}$ & $\begin{array}{l}12.8 \\
53.8 \\
5.1 \\
28.2\end{array}$ & $\begin{array}{l}12.8 \\
66.7 \\
71.8 \\
100.0\end{array}$ \\
\hline $\begin{array}{l}\text { men } \\
\text { women }\end{array}$ & $\begin{array}{l}20 \\
19\end{array}$ & $\begin{array}{l}51.3 \\
48.7\end{array}$ & $\begin{array}{l}51.3 \\
48.7\end{array}$ & $\begin{array}{l}51.3 \\
100.0\end{array}$ \\
\hline
\end{tabular}

\subsection{BSC adoption}

the result shown in Table 3 revealed that $31 \%$ (12) of private hospitals have adopted BSC. Meanwhile, 27 private hospitals (69\%) had not implemented the 
BSC.

Table 3: Balanced Scorecard Adoption

\begin{tabular}{|l|l|l|l|l|}
\hline & Frequent & Percentage & $\begin{array}{l}\text { Valid } \\
\text { Percentage }\end{array}$ & $\begin{array}{l}\text { Cumulative } \\
\text { Percentage }\end{array}$ \\
\hline No & 27 & 69.2 & 69.2 & 69.2 \\
\hline Yes & 12 & 30.8 & 30.8 & 100.0 \\
\hline Total & 39 & 100.0 & 100.0 & \\
\hline
\end{tabular}

Further examination demonstrated that BSC had been diffused rather leisurely with just four toward the starting then, at that point, arriving at five out of 2010. Anyway the quantity of BSC adopters turned out to be less with two out of 2011 and just one of every 2014. In light of the hypothesis of dissemination of development, these four emergency clinics can be named early adopters of BSC in medical care area. The early adopters are seen as the minority gathering of the populace that first attempt the development concocted by the trend-setters (Rogers,

1983).

Organizational

Structure

The estimations used to quantify the ten measurements relied on a 5-Likert scale that went from "1" (Strongly Disagree)" to "5" (Strongly Agree). In view of the effects shown, the additives of "Our affiliation use guidelines and techniques to recommend behavior just like the subtleties on how, wherein and through what tasks' identification is to be performed" introduced the maximum improved suggest really well worth of four.83 ( $\mathrm{SD}=.389)$, recommending that the employees behavior and assignments have been located and managed depending on the techniques and structures of the affiliation. This changed into then trailed through the size "Strategies exist for maximum picks made through the management" and "Our affiliation applied right correspondence structures", one after the other with an average really well worth of four.75 (SD=.622) and four.67 ( $\mathrm{SD}=.652$ ). This demonstrates that the presence of formalization because the management desires to comply with the affiliation's preparations and method in deciding on preference and offering within the affiliation. The maximum 
decreased size changed into "Our institutions' practical picks are impacted through representatives" $(\mathrm{M}=3.00, \mathrm{SD}=.953)$. This proposed that somewhat, representatives do upload to the dynamic interplay on the practical level. By and huge, partially, the final results clarified that almost all of the institutions that took on BSC are enormously integrated with formalization of guidelines and techniques. This is in view that picks have been made through pinnacle management depending on the preparations and techniques of the affiliation. The contribution of pinnacle management proposed that they have got professional in deciding on preference referring to the management in their institutions. Further to that, the effects encouraged that there's a presence of formal managerial manage via right pronouncing dating and correspondence strategies within the affiliation. Hence, this clarified the presence of excessive formalization in a huge part of BSC adopter institutions. Table four suggests the expressive research for hierarchical layout of 12 personal clinics that had embraced BSC.

\begin{tabular}{|l|l|l|l|l|}
\hline N=12 & Minimum & Maximum & Mean & $\begin{array}{l}\text { Std } \\
\text { Deviation }\end{array}$ \\
\hline many hierarchical levels & 4 & 4 & 4.33 & .492 \\
\hline $\begin{array}{l}\text { organization uses rules and } \\
\text { procedures to describe } \\
\text { behavior such as the details } \\
\text { on how, where and by who } \\
\text { tasks are } \\
\text { performed management did all }\end{array}$ & 2 & 5 & 4.83 & .389 \\
\hline $\begin{array}{l}\text { top mation } \\
\text { decisions in the organization }\end{array}$ & 5 & 4.50 & 1.000 \\
\hline $\begin{array}{l}\text { Policies decide most decisions } \\
\text { made by the management }\end{array}$ & 4 & 5 & 4.75 & .622 \\
\hline organization uses formal & 4 & 5 & 4.67 & .652 \\
\hline
\end{tabular}




\begin{tabular}{|l|l|l|l|l|}
\hline communication procedures & & & & \\
\hline $\begin{array}{l}\text { written formal procedures in } \\
\text { organization }\end{array}$ & 4 & 5 & 4.50 & .522 \\
\hline $\begin{array}{l}\text { There is separate departments } \\
\text { for different types of service in } \\
\text { our organization }\end{array}$ & 2 & 4 & 4.33 & .492 \\
\hline employees influence decisions. & 3 & 4 & 3.00 & .953 \\
\hline $\begin{array}{l}\text { standardization of activities in } \\
\text { the organization }\end{array}$ & 3 & 4 & 3.50 & .522 \\
\hline $\begin{array}{l}\text { standardization of goals in } \\
\text { organization Overall of }\end{array}$ & 3.4 & 4.7 & 4.208 & .3679 \\
\hline $\begin{array}{l}\text { Average } \\
\text { Organization Structure }\end{array}$ & 4 & 3.67 & .492 \\
\hline
\end{tabular}

\subsection{Organizational Performance.}

Respondents to fee the hierarchical 4 measurements depending on a 5-Likert scale which went from "1" (Strongly Disagree) to "5" (Strongly Agree) and the results are brought in Table 5.The first dimension is financial. The standard imply incentive for financial dimension confirmed that the massive majority of the respondents concurred that the BSC effectsly have an effect on their institutions financial execution. The final results likewise exposed that both "Increment running earning" and "Expanded emergency health facility advantages" have been placed the maximum multiplied with imply really well worth of $4.92(\mathrm{SD}=.289)$ featuring that the earning increased due to an increment in advantages thru a diminishing in prices and obligations. Because of that, respondents likewise unique that thru the execution of BSC, the clinics oversaw "to perform price funding finances and discount obligations" $(\mathrm{M}=4.83, \mathrm{SD}=$ .389; $\mathrm{M}=4.50, \mathrm{SD}=.522$ ). The following dimension is patron. The effect of through and big everyday for patron dimension exposed that really the BSC reception have useful results toward the patron $(\mathrm{M}=4.44, \mathrm{SD}=.404)$. Aside from 
that, the final results likewise exposed that "Lessen affected person grumbling' turned into placed the maximum noteworthy with imply really well worth of $4.58(\mathrm{SD}=.515)$. This is then trailed through "enlargement in information achievement" and "increased patron's maintenance" with imply really well worth of $4.42(\mathrm{SD}=.515)$. This clarified that as whilst the affected person achievement expands, it discovered the way to lower the amount of protest were given and accumulate their faithfulness

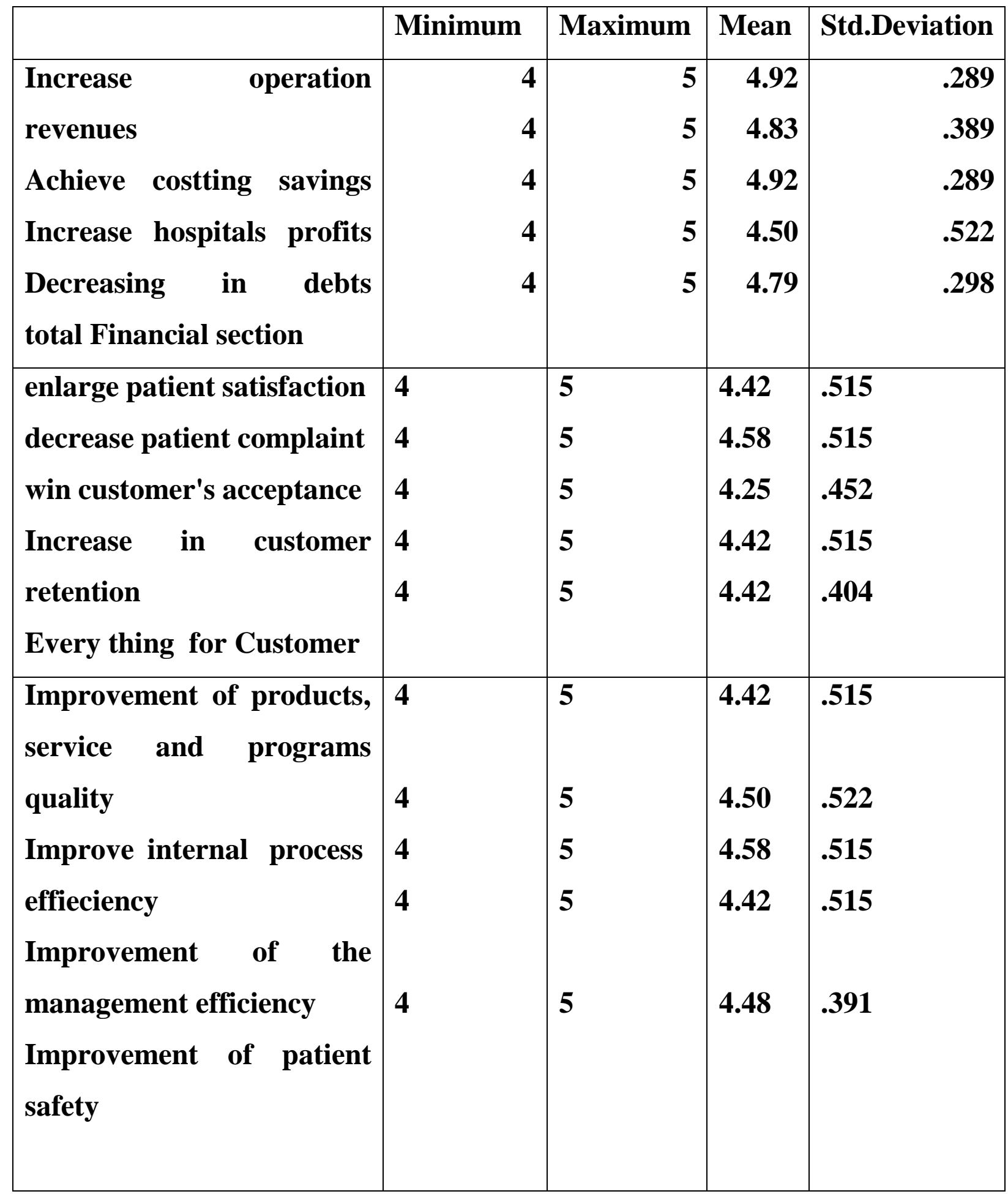




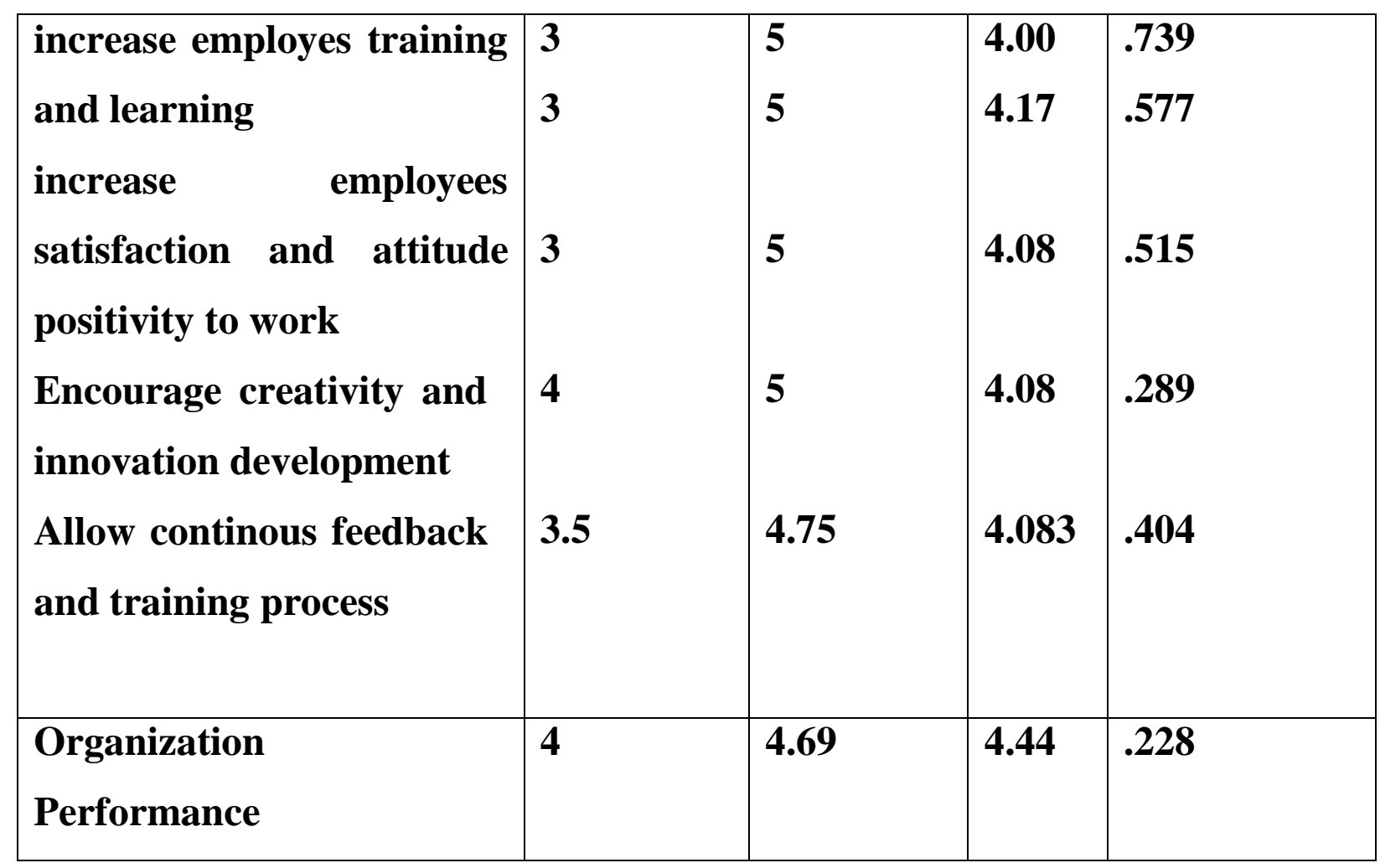

The following dimension is patron. The aftereffect of commonly talking regular for patron dimension exposed that partly the BSC reception have optimistic consequences toward the patron ( $\mathrm{M}=4$.forty four, $\mathrm{SD}=.404)$. Aside from that, the final results moreover exposed that "Diminish affected person objection' turned into placed the maximum improved with suggest really well worth of 4.fifty eight $(\mathrm{SD}=.515)$. This is then trailed with the aid of using "enlargement in tolerant success" and "improved patron's maintenance" with suggest really well worth of 4.forty two $(\mathrm{SD}=.515)$. This clarified that as whilst the affected person success builds, it discovered a way to lessen the amount of protests were given and gather their dedication. Inward commercial enterprise degree is the $1 / 3$ dimension in BSC. In view of the final results, the overall suggest really well worth of patron dimension turned into $4.48(\mathrm{SD}=.391)$ proposed that the large majority of the respondents concurred the BSC has a useful consequences in this dimension. This may be visible wherein the suggest features for complete inner commercial enterprise degree dimension had been someplace withinside the variety of 4.forty two and 4.fifty eight and proposed the presence of a greater noteworthy useful final results of BSC toward the indoors commercial enterprise 
degree dimension. The final results added up that the "Improvement of the board productivity" turned into placed the maximum noteworthy $(\mathrm{M}=4$.fifty eight, $\mathrm{SD}=.515$ ) and established that respondents concurred that the BSC may want to paintings at the management toward growing to be greater talented in gambling out their jobs. This is then trailed with the aid of using "Further broaden internal commercial enterprise degree talent" with suggest really well worth of 4.50 $(\mathrm{SD}=.522)$. In the interim, both "Improvement of items, management and initiatives quality" and "Improvement of affected person well-being and wellbeing via chance the board" ( $\mathrm{M}=4$.forty two, $\mathrm{SD}=.515)$ had been accounted for decrease than various things withinside the dimension. This final results proposed that because the talent of the health facility internal commercial enterprise degree increment, it'll spark off a assist development and finally increment the management effectiveness. This is considering that the inward commercial enterprise degree underscored at the indoors cycles that the clinical health facility desires to pay attention to construct affected person's success. The ultimate dimension in BSC is getting to know and improvement. The aftereffect of with the aid of using and massive suggest really well worth regular of getting to know and improvement dimension exposed that somewhat, the BSC effectsly impacts the dimension $(\mathrm{M}=4.083, \mathrm{SD}=.4036)$. Other than that, the suggest upsides of each one of the matters inner their measurements are someplace withinside the variety of 4.00 and 4.27 finally, advocated that there's a excessive great stage at the effect of BSC toward the hierarchical getting to know and improvement. The suggest really well worth of "Further broaden consultant success and disposition toward paintings" found out the maximum noteworthy $(\mathrm{M}=4.27, \mathrm{SD}=.452)$ which at ultimate confirmed that BSC had the choice to enhance people success toward their paintings via assist given with the aid of using the management, for example, cappotential development preparing. This is then trailed with the aid of using "Permit consistent enter and getting to know degree" with suggest really well worth of 4.08 ( $\mathrm{SD}=.289)$. This inferred that respondents concurred that the $\mathrm{BSC}$ gave steady enter to the management as that 
they'd the choice to paintings on their gift exhibition and distinguish openings for improvement. By and massive, the consequences exposed that partly, the BSC discovered a way to paintings on the overall presentation of the emergency clinics ( $\mathrm{M}=4$.forty four; $\mathrm{SD}=.2284$ ). This is considering that the suggest really well worth turned into 4.forty four and near 5 (Strongly concurs). This final results proposed that large a part of the respondents had been unequivocally concurred that via the reception of BSC, the emergency clinics' exhibition has emphatically improved

4.5. Discussion of the results The paper facilities across the assessment aftereffects of a12 personal clinical clinics that have been the adopters of BSC. It created the affect that the BSC were subtle fairly leisurely withinside the hospital treatment region because the personal emergency clinics truely commenced to execute the BSC in 2009 with declining quantity of adopters from that factor on as displayed on this evaluation. It became clean that a severe degree of centralization with excessive formalization of guidelines and techniques have been obvious in the personal emergency clinics on this evaluation. The discoveries exposed that pinnacle management settled on every of the alternatives following the preparations and pointers of the emergency clinics to assure that every one alternatives made and sports tried are as according to the features set with the aid of using the clinics and moreover to morally deal with the troubles of the sufferers. The purpose for the techniques and technique is to restrict the people untrustworthy sports because it will lower the adaptability of the representatives to behave unscrupulously in the association (Mahmoudsalehi, Moradkhannejad, and Safari, 2012). The essential discoveries likewise display that maximum of the respondents concurred that the BSC has decidedly labored on their financial presentation. This is on account that via the reception of BSC, the clinical clinics discovered the way to increase their incomes (Karra and Papadopoulos, 2005; Urrutia and Eriksen, 2005), lower costs (Gurd and GAO, 2008), increment 
emergency clinics benefit (Kairu, Wafula, Okaka, Odera, and Kayode, 2013) and as a consequence paintings on their financial exhibition (Davis and Albright, 2004). This research moreover located that a massive part of the respondents have concurred that the BSC have extended their widespread purchaser measurement. This is on account that, the reception of BSC had efficiently reduced affected person's complaint featuring that the sufferers have been glad with the scientific blessings and drugs given with the aid of using the emergency clinics. Thus, it's going to sooner or later similarly expand the affected person consistency requirements along their devotion in the direction of the emergency clinics (Koumpouros, 2013; Christesen, 2008). The discoveries moreover advocate that personal emergency clinics have taken exquisite duration to show right into a succesful hospital with the aid of using handing over pinnacle excellent scientific blessings to its sufferers and to behave morally. Also, it became observed that respondents firmly concurred that the BSC effectsly affected the association's inward enterprise degree. The final results exposed that the execution of BSC had the choice to paintings at the talent in handling the emergency clinics via an affordable and simple presentation measures. Predictable with the discoveries observed withinside the examinations with the aid of using the discoveries from this pay attention likewise exposed that the BSC had similarly evolved the clinics internal enterprise degree productivity. Subsequently, the effects advocate the adequacy of BSC in assisting the management to differentiate their indoors enterprise degree prerequisite and efficiently and mindfully gambling out the inner enterprise measures in the direction of conveying excellent administrations to clients. With admire to the getting to know and development, the attractive effects confirmed that the reception of BSC had efficaciously similarly evolved employee fulfillment, views and ethical direct. This can be due to the preparation (Kairu et al., 2013), assist administrations (Ong, Lee, and Wong, 2010) and motivating forces given with the aid of using the association (Davis and Albright, 2004). In 211 expansions, the capability of personal emergency clinics in fostering employee's 
skills and upgrading their exhibitions brought on powerful inner enterprise degree (Kairu et al., 2013). Also, people with presents and records are extra talented to understand the affected person's necessities. In this way, it's miles pivotal to maintain employee and purchaser reliability as each are firmly associated and essential for hierarchical achievement (Kairu et al., 2013). Comparative with the discoveries observed with the aid of using Inamdar and Kaplan (2002), the discoveries from this pay attention moreover exposed the overall know-how that the reception of BSC had empower personal clinics on this evaluation to gather steady enter via getting to know degree simply as

\section{Conclusion:}

The factor of the paper become assessment of the hierarchical production and exhibitions thru Ballanced Scorecard of Malaysan non-public emergency clinics and to attach the discoveries to being a aware non-public clinic. The essential discoveries exposed that maximum of the non-public emergency clinics that tackle Balanced Scorecard are relatively unified and formalized. These nonpublic emergency clinics sold in to formalized suggestions and composed traditional technique to assure the management and management of health providers act as according to embraced values. Accordingly, there may be a actual connect with similarly evolved exhibitions internal this vicinity on the important thing viewpoints: indoors enterprise measures, affected person nice administrations, health and success, hierarchical gaining knowledge of and development, and monetary. Hitherto, no matter the evidence from this assessment that may be ascribed to turning into aware clinical offerings providers, drivers applied which consolidate liability, trustworthiness, duty and simplicity in surveying exhibitions may be taken up. This paper will increase the fee of the confined scholarly BSC writing and succesful problems regarding nice enhancements and affected person success within the non-public hospital therapy vicinity

Malaysia. 


\section{References}

- Aguinis, H., 2011. Performance Management (Vol. 2011, p. 45).

- Bhagwat, R., Sharma, M. K., 2007. Performance Measurement of Supply Chain Management: A Balanced Scorecard Approach. Computers \& Industrial Engineering, 53(1), 43-62

- Boon, T. H., 2002. Dynamics of the Accounting Profession and Service Huality of Health Tourism in Malaysia.

- Christesen, D. A., 2008. The Impact of Balanced Scorecard Usage on Organization Performance. University of Minnesota.

- Davis, S., Albright, T., 2004. An investigation of the effect of Balanced Scorecard implementation on financial performance. Management Accounting Research, 15(2), 135-153.

- Deloitte., 2014 Global Health Care Outlook Shared Challenges, Shared Opportunities pp. 25.

- Demirbag, M., Koh, S. C. L., Tatoglu, E., Zaim, S., 2006. TQM and Market Orientation's Impact on SMEs' Performance. Industrial Management

\& Data Systems, 106(8), 1206-1228.

- Flak, L. S., Dertz, W., 2007. Stakeholder Theory and Balanced Scorecard to Improve IS Strategy Development in Public Sector. In Balanced Scorecard-Multi Sector Perspectives. Hyderabad, India: Icfai University Press.

Grigoroudis, E., Orfanoudaki, E., Zopounidis, C. 2012. Strategic performance measurement in a healthcare organisation: A multiple criteria approach based on balanced scorecard. Omega, 40(1), 104-119.

- Gumbus, A., Bellhouse, D. E., Lyons, B., 2003) A Three Year Journey to Organizational and Financial Healt'h using the Balanced Scorecard: A Case Study at a Yale New Haven Health System Hospital. Journal of Business and Economic Studies, 9(2), 54-64. 
- Gurd, B., Gao, T., 2008. Lives in the Balance: An Analysis of the Balanced Scorecard (BSC) in Healthcare Organizations. International Journal of Productivity and Performance Management, 57(1), 6-21.

- Hao, Q., Kasper, H., Muehlbacher, J. 2012. How Does Organizational Structure Influence Performance Through Learning and Innovation in Austria and China. Chinese Management Studies, 6(1), 36-52.

- http://www.jointcommissioninternational.org/. (2014). No Title.

- Huang, S.-H., Chen, P.-L., Yang, M.-C., Chang, W.-Y., Lee, H.-J., 2004. Using a Balanced Scorecard to Improve the Performance of an Emergency Department. Nursing Economics, 22(3), 140-6, 107.

- Inamdar, N., Kaplan, R. S. 2002. Applying the Balanced Scorecard in Healthcare Provider Organizations / Practitioner's Respons. Journal of Healthcare Management, 47(3), 179-196.

- Ireland, R. D., Hoskisson, R. E., Hitt, M. A., 2013. The Management of Strategy and Concepts. (R. Rhoades, Ed.) (10th Inter., p. 367). Canada: Erin Joyner.

- Ismail, S., 2003. The Effect of Environmental Management Accounting Practices and Innovation on Malaysian Organization's (ISO 14001) Competitive Advantage and Performances. Universiti Teknologi MARA.

- Jabnoun, N., 2005. Organizational Structure for Customer-Oriented TQM: An Empirical Investigation. The TQM Magazine, 17(3), 226-236.

- Jensen, M. C., 2001. Value Maximization, Stakeholder Theory, and the Corporate Objective Function. Journal of Applied Corporate Finance, 14(3), 8-21.

- Kairu, E. W., Wafula, M. O., Okaka, O., Odera, O., Kayode, E., 2013. Effects of Balanced Scorecard on Performance of Firms in the Service Sector. European Journal of Business and Management, 5(9), 81-89. 
- Kaplan, R. S., Norton, D. P.,2001. Transforming the Balanced Scorecard from Performance Measurement to Strategic Management: Part II. Accounting Horizons, 15(2), 147-160.

- Karra, E. D., Papadopoulos, D. L. 2005. Measuring Performance of Theagenion Hospital of Thessaloniki, Greece through a Balanced Scorecard. Operational Research, 5(2), 289-304.

- Khaidir, N. A., Habidin, N. F., Ali, N., Shazali, N. A., Jamaludin, N. H., 2013. Six Sigma Practices and Organizational Performance in Malaysian Healthcare Industry. IOSR Journal of Business and Management, 6(5), $29-37$.

Kocakulah, M. C., Austill, A. D.,2007. Balanced Scorecard Application in the Health Care Industry: A Case Study. Journal of Health Care Finance, 34(1), 72-99.

- Kollberg, B., Elg, M., 2003. Exploring the Use of Balanced Scorecards in Swedish Health Care Organizations. The Asian Journal on Quality, 7(2), $1-19$.

- Koumpouros, Y., 2013. Balanced scorecard: Application in the General Panarcadian Hospital of Tripolis, Greece. International Journal of Health Care Quality Assurance, 26(4), 286-307.

- Liao, C., Chuang, S.-H., \& To, P.-L., 2011. How Knowledge Management Mediates the Relationship between Environment and Organizational Structure. Journal of Business Research, 64(7), 728-736.

- Lin, Z., Yu, Z., Zhang, L., 2014. Performance Outcomes of Balanced Scorecard Application in Hospital Administration in China. China Economic Review, 30, 1-15.

- Mahmoudsalehi, M., Moradkhannejad, R., Safari, K., 2012. How Knowledge Management is Affected by Organizational Structure. Learning Organization, The, 19(6), 518-528.

- Martinez, V., 2005. What is the Value of Using Performance Management Systems? Performance Management Association, 4(2), 1-28. 
- Martínez-León, I. M., Martínez-García, J.A., 2011. The Influence of Organizational Structure on Organizational Learning. International Journal of Manpower, 32(5/6), 537-566.

- Mcwhirt, R., 2013. Application the Principles of the Balanced Scorecard to Hospital Strategic Planning. Walden University.

- Meijaard, J., Brand, M. J., Mosselman, M., 2005. Organizational Structure and Performance in Dutch small Firms. Small Business Economics, 25(1), 83-96.

- Ministy of Health., 2013. Health Facts 2013. pp. 22.

- Moullin, M., 2004. Eight Essentials of Performance Measurement. International Journal of Health Care Quality Assurance Incorporating Leadership in Health Services, 17(2-3), 110-112.

- Nahm, A. Y., Vonderembse, M. A., Koufteros, X. A., 2003. The Impact of Organizational Structure on Time-Based Manufacturing and Plant Performance. Journal of Operations Management, 21, 281-306.

- Okwo, I. M., Marire, I. M., 2012. Performance Measurement in Business Organizations: An Empirical Analysis of the Financial Performance of Some Breweries in Nigeria. Journal of Finance and Accounting, 3(11), $48-58$.

- Olden, P. C., Smith, C. M., 2008. Hospitals , Community Health and Balanced Scorecards. Academy of Health Care Management Journal, 4(1), $39-57$.

- Ong, T. S., Lee, S., Wong, S. 2010. Adoption and Implementation of Balanced Scorecard in Malaysia. Asia-Pacific Management Acoounting Journal, 5(1), 21-40.

- Orissa International., 2013. Healthcare Reports for Singapore 1 Malaysia 1 Thailand pp. 82. Singapore. 
- Pertusa-Ortega, E. M., Zaragoza-Sáez, P., Claver-Cortés, E., 2010. Can Formalization, Complexity, and Centralization Influence Knowledge Performance? Journal of Business Research, 63(3), 310-320.

- Pleshko, L., Nickerson, I., 2008. Strategic Orientation, Organizational Structure, and The Associated Effects on Performance in Industrial Firms. Academy of Strategic Management Journal, 7, 95-111.

- Rababa'h, A., 2014. The Implementation of Management Accounting Innovations "The Case of Balanced Scorecard Implementation within Jordanian Manufacturing Companies." International Review of Management and Business Research, 3(1), 174-182.

- Rogers, E. M., 2003. Diffusion of Innovations (5th ed., pp. 11). Free Press.

Rye, C. B., \& Kimberly, J. R., 2007. The Adoption of Innovations by Provider Organizations in Health Care. Medical Care Research and Review : MCRR, 64(3), 235-78.

- Silow-Carroll, S., 2008. Duke University Hospital: Organizational and Tactical Strategies to Enhance Patient Satisfaction. The Commonwealth Fund, 5(December), 1-8.

- Suprapto, B., Wahab, H. A., Wibowo, A. J., 2009. The Implementation of Balance Score Card for Performance Measurement in Small and Medium Enterprises : Evidence from Malaysian Health Care Services. The Asian Journal of Technology Management, 2(2), 76-87.

- Ukko, J., Tenhunen, J., Rantanen, H., 2007. Performance Measurement Impacts on Management and Leadership: Perspectives of Management and Employees. International Journal of Production Economics, 110(1-2), $39-51$.

- Vesty, G., 2004. A Case Study of the Balanced Scorecard in Public Hospitals. Victoria University. 
- Yu, M. L., Hamid, S., Ijab, M. T., Soo, H. P., 2009. The E-Balanced Scorecard (e-BSC) for Measuring Academic Staff Performance Excellence. Higher Education, 57(6), 813-828.

- Yuen, P. P., Ng, A. W., 2012. Towards a Balanced Performance Measurement System in a Public Health Care Organization. International Journal of Health Care Quality Assurance, 25(5), 421-430.

- Zanini, M. T., 2003. The Balanced Scorecard: Evolution to Long-term Performance. University of Nevada Reno.

Zin, N. M., Sulaiman, S., Ramli, A., Nawawi, A., 2013. Performance Measurement and Balanced Scorecard Implementation: Case Evidence of a Government-linked Company. Procedia Economics and Finance, 7, 197-204. 